\title{
C product plastic mould cavity from form solution
}

\author{
Yumei LIU \\ Binzhou Polytechnic Mechanical Engineering, Shandong Binzhou, china,256603; \\ E-mail:lym_1209@163.com
}

Keywords: plastic mold, open mold from shape, stick front mould.

\begin{abstract}
The commonly used to open mold from form solution contains strengthening front mould polishing, increase the front mould stripping Angle, front mould and play the roof structure, strengthening back mould bag tight force to wait for a few kinds, in view of the $\mathrm{C}$ product cavity from shape, various solutions to one argument, a final determination in products after reinforcement to mold as the most suitable solutions.

With the improvement of manufacturing industry, mould will to a wide range of areas and higher level development. Facing the increasingly competitive die market, customer's size accuracy and cosmetic requirements are more and more high, plastic products structure shape also is complicated, to request molding tool also will more and more high.

Open mode shape also called sticky from front mould, is open mold moment by mold front mould drive products to form defects products, including a general appearance defects products or even pull deformation, cause not normal, plastic injection molding. Open mode shape is mold from the mold to try the production stages widely existing problems point, leading to the production of the products in the stability of high, directly influence the products quality and delivery, commonly used to open mold from form solution contains the following kinds:

1. Strengthen front mould polishing. Reduce the surface roughness of the former model cavity, can reduce the cavity mould products before the friction, prevent scratch products. (soft rubber as the surface roughness to increase the adhesion of cavity the lower mold force, so for the soft rubber products instead of to increase the front mould roughness.)

2. Increase the front mould stripping Angle. Increase the front mould stripping Angle can also reduce the model of the products before cavity friction, but increase the Angle will affect stripping goods size, before these changes need to communicate with customers this method is feasible and has no impact on the products under the condition of the look and function to increase the stripping Angle.

3. Front mould and play the top structure. Products normally in the open after the top of the mould by the organization accomplish ejector, make products to be able smoothly from the cavity. But when products in front mould forming of mould kernel of a sticky mold force is too big, products can't smooth from front mould, cause products have scratches on the surface or even pull deformation, also can pass in front mould add ejector institutions to assist products from front mould. The most commonly used is to add the top institutions, namely simple save a space again.

4. Strengthen back mould bag tight force. By increasing the forming glue a, after increasing to attend or after module bite flowers and discharge, and other ways to increase the products after the stick to die mold force to offset mould products before too much tension, the products smooth emerge front mould.

As shown in figure 1, this set of mould product is a demand higher electronic product shell, can be seen in the graph, the product structure is not complex, the open mold cavity assessment not made from the shape of a judge, but through the early try mould found serious scratch products, in order to solve this problem, above all used scheme, and finally, by strengthening the mold bag after the way tight force improved defects.
\end{abstract}



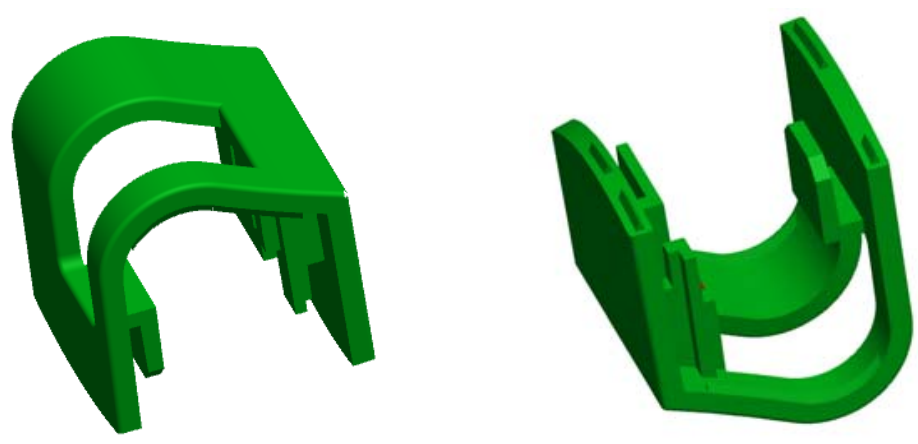

Fig. 1

First try mode, found open mold from form at the problem, because the product surface requirements has reached highlights, so to strengthen the rule out front mould polishing plan, the increasing front mould mold pulling out Angle, as shown in figure 2 shows.
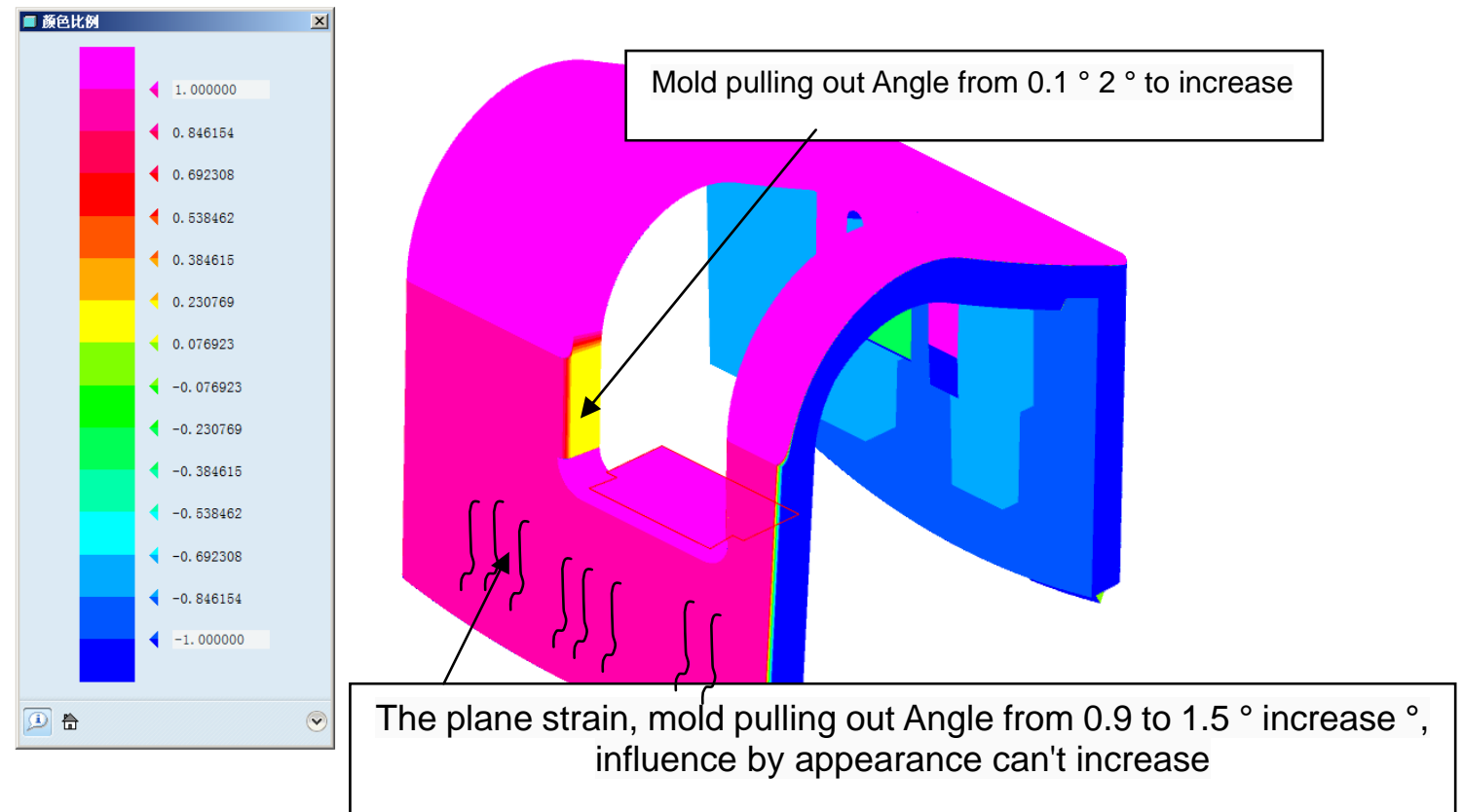

Fig. 2

The second test mode, found open mold from form not improved, to die surface discharge lines treatment, discharge grain is equivalent to VDI30, pour quantity in $0.03 \mathrm{~mm}$ or so, as shown in figure 3 shows.

The third try mode, open mold from form is still not improved, in view of this kind of simple products three times not OK, the product quantity production delivery nervous, try mould meeting decided to add the top front mould structure, mould opening moments, top, in and out of the spring son under the action of the top product, as shown in figure 4. 


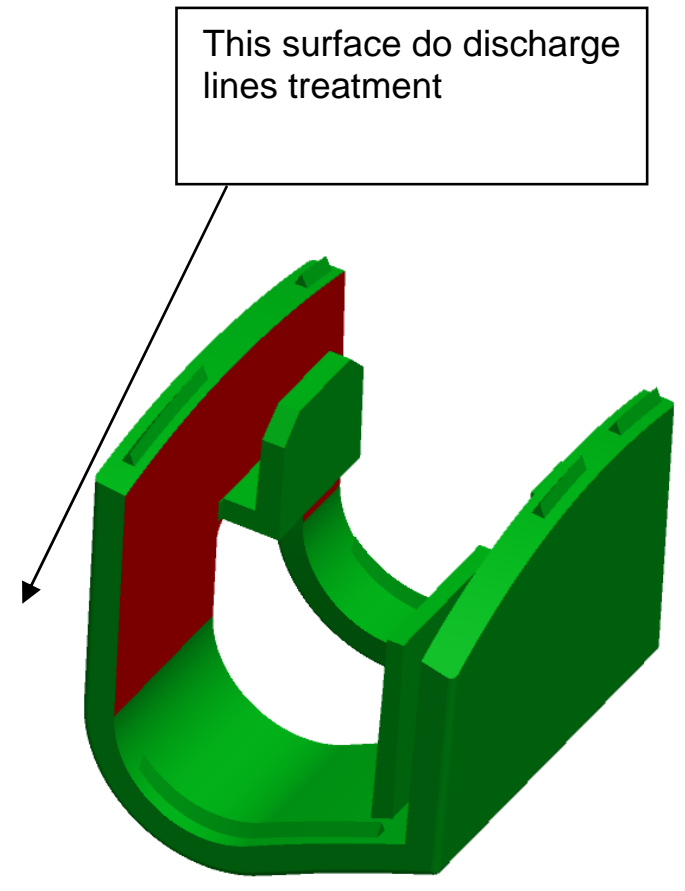

Fig. 3

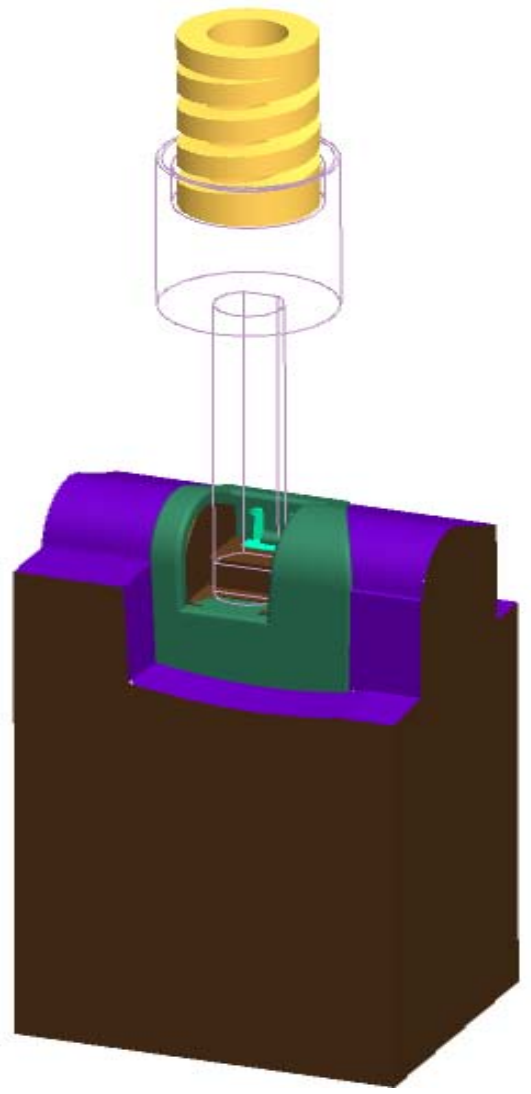

Fig. 4

The fourth try mode, the effect is not obvious, the strain has been improved, but cannot batch production, careful analysis, open mold from the root cause of the form or back mould to force is not enough, the study in the product back mould reinforcement grasp, reinforcement of a way shown as shown in figure 5.

The product contrast diagram deformation
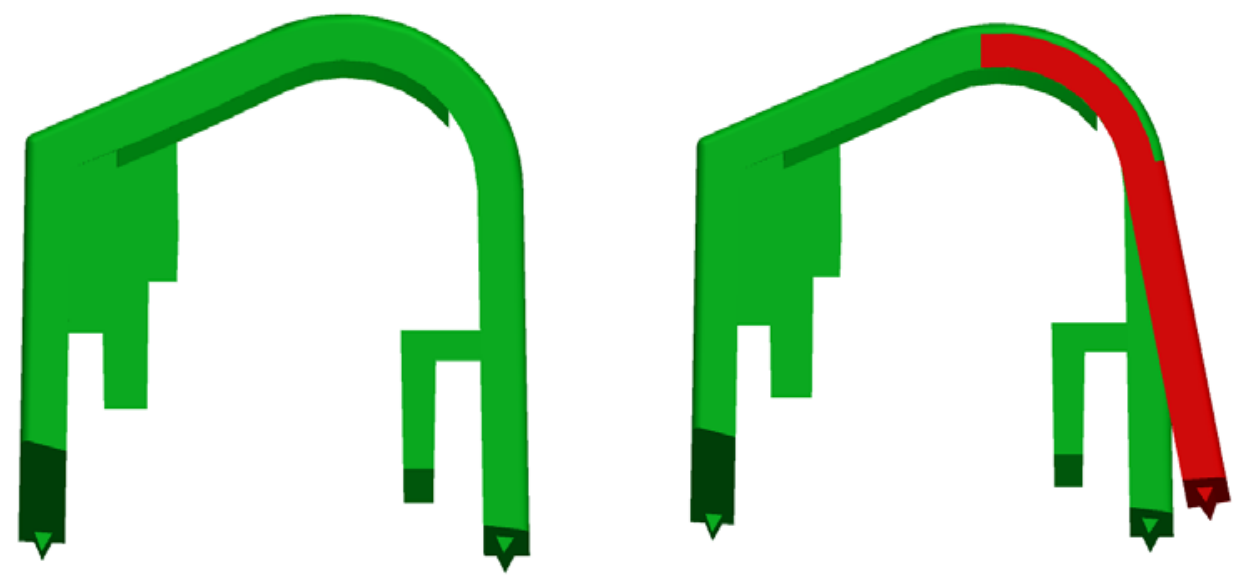

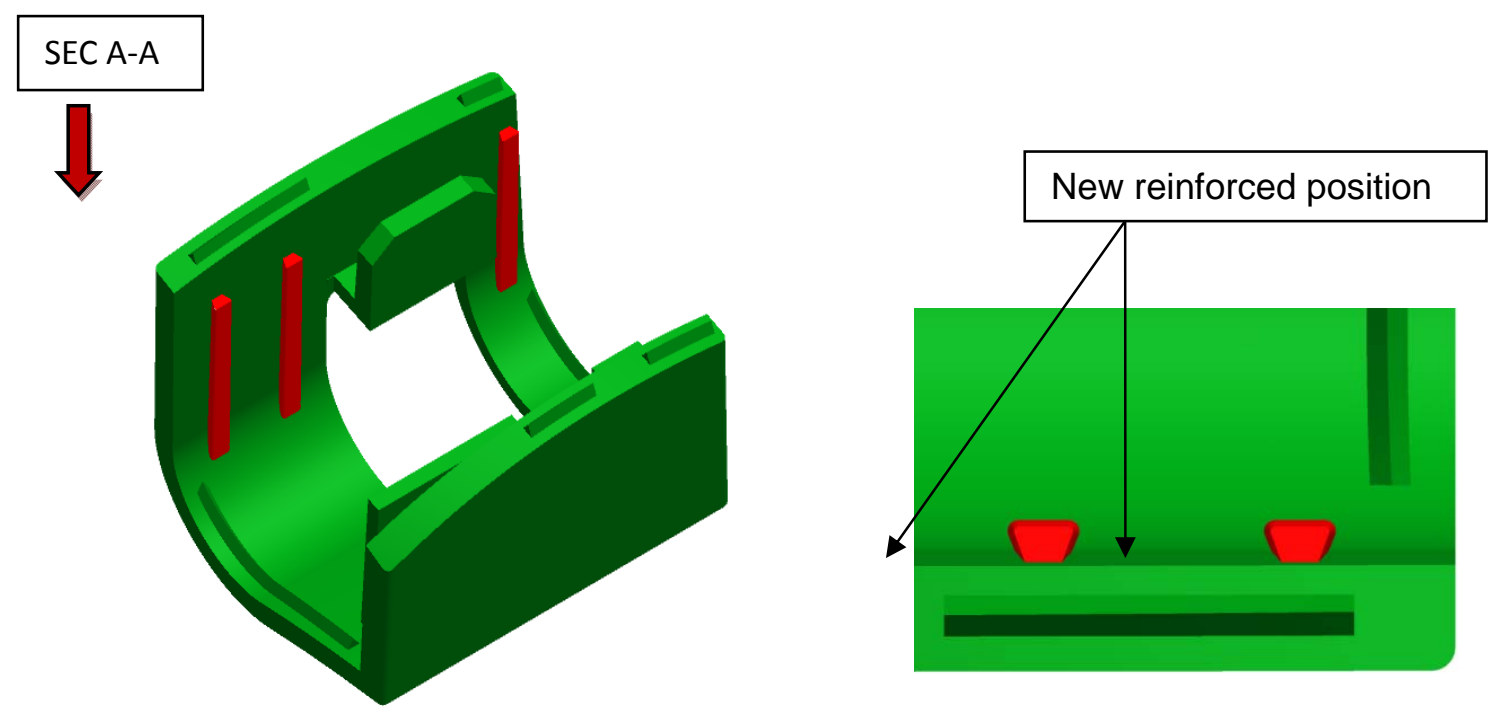

Fig. 5

Pictured above the muscles of a type special increase: because the product assembly interference, the space is limited, the product shape serious, a common reinforcement to force enough, prevent deformation improve the effect not beautiful, in this type of product $\mathrm{C}$ open mold from shape, the reinforcement effect is good, it is recommended to use.

Through this modification, open mold from form the problems were solved, realize the mass production.

\section{References}

[1] XuFa Yue. Die design and manufacture practical manual. Mechanical industry press. 1999:298-483.

[2] TanXueSong, LinXiaoXin, WenLi. New plastic mould design manual. People's posts and telecommunications publishing house. 2007:101-109.

[3] ZhangWeiGe. Injection mold design practical tutorial. Chemical industry press. 2007:.

[4] GeZhengHao. Pro/E injection mold design example tutorial. Chemical industry press. 2007.

[5] ZhouJunChen. Pro/e Chinese version plastic mould design expert wildfires earnestly example. Chinese youth press. 2006. 